\title{
A Spatial Perspective on European Integration: Heterogeneous Welfare and Migration Effects from the Single Market and the Brexit
}

\author{
Marcel Henkel \\ Tobias Seidel
}

CESIFO WORKING PAPER NO. 6289

CATEgORY 8: TRAde Policy

DECEMBER 2016

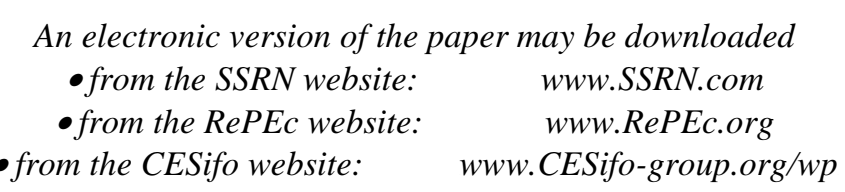




\title{
A Spatial Perspective on European Integration: Heterogeneous Welfare and Migration Effects from the Single Market and the Brexit
}

\begin{abstract}
We use a quantitative model to study the implications of European integration for welfare and migration flows across 1,318 regions. The model suggests that an increase of trade barriers to the level of 1957 reduces welfare by about 1-2 percent on average, depending on the presumed trade elasticity. However, remote regions may face initial welfare losses of up to 4 percent causing an estimated migration of about 8 million individuals to the European core. This implies that the dismantling of trade barriers in Europe has led to a more homogeneous spatial distribution of economic activity. With regard to the Brexit, we find moderate welfare losses for the UK of -0.44 percent in the most pessimistic scenario while continental Europe's welfare declines by 0.18 percent. In the most unfavorable scenario, about 500,000 people would leave the UK in the long run.
\end{abstract}

JEL-Codes: F100, F120, F150, R110, R120, R130, R230.

Keywords: regional integration, labor mobility, spatial inequality.

Marcel Henkel

University of Duisburg-Essen

Mercator School of Management

Lotharstraße 65

Germany - 47057 Duisburg

marcel.henkel@uni-due.de
Tobias Seidel*

University of Duisburg-Essen

Mercator School of Management

Lotharstraße 65

Germany - 47057 Duisburg

tobias.seidel@uni-due.de 


\section{Introduction}

We know at least since the times of Adam Smith and David Ricardo that the integration of markets promises welfare gains for all participating countries. However, the spatial dimension of these welfare gains within countries and the associated migration patterns are less understood. Recent developments of rigorous quantitative models that incorporate regions and free mobility of workers between locations (e.g. Allen and Arkolakis, 2014, Behrens, Mion, Murata, Suedekum, 2017, Redding, 2016) allow us to address this topic. In this paper, we take a closer look at European integration by applying the spatial perspective. Which regions benefitted most from the dismantling of trade barriers and what migration pattern did these heterogeneous welfare effects cause? Addressing these questions aims at a better understanding of the spatial allocation of economic activity in Europe.

We combine a unique data set on inter-regional trade flows in Europe with a quantitative spatial model and analyze two events in the integration process of Europe. First, we raise trade costs to the level before the Common Market was established in 1957. According to Levchenko and Zhang (2012), trade costs in the European Union were about 45 percent higher in the 1960s compared to the 2000s. As substantial trade cost reductions took place with the founding of the European Community in 1957, we run our counterfactual with 60 percent higher trade costs across national borders. Second, we estimate welfare changes and implied migration flows for regions within the UK and in other European countries after the Brexit. Following Dhingra et al. (2016), we distinguish between an optimistic scenario where trade costs increase by about 3.7 percent and a pessimistic scenario with a 13.9-percent increase in trade barriers. These counterfactuals inform us about the magnitude of effects and - more importantly - about (relative) winners and losers across 1,318 NUTS-3 regions.

The model predicts moderate welfare losses of 1-2 percent when we withdraw the market integration steps since the introduction of the European Community in 1957. These welfare effects are distributed very heterogeneously across regions. The periphery experiences welfare losses that are up to six times larger than those in some core regions, so migration is triggered from remote locations to the European center. In our baseline scenario, the model suggests overall migration of 8.1 million individuals or 1.6 percent of the European population. In alternative scenarios, these figures rise to 11.4 million or 2.3 percent, respectively. European integration has therefore contributed to a more homogeneous distribution of economic activity.

The Brexit is associated with an increase of trade costs between the UK and the rest of Europe at national borders. As trade frictions between intra-national regions and across all other national borders remain unchanged, the model predicts only small welfare effects ranging between -0.2 and -0.44 percent for the UK in the pessimistic scenario. The EU, 
in contrast, is much less affected with welfare losses being only half of those in the UK on average. These heterogeneous effects trigger migration of up to one million individuals in the most unfavorable scenario and with free migration across European regions. In that case, more than 500,000 individuals from the UK would relocate to the European Union. If migration is only allowed within UK boundaries, only 14,000 to 53,000 people migrate to equalize welfare differences within the country. In all scenarios, Scotland faces the largest losses in terms of welfare and hence the largest outmigration of people.

It is well understood that single-sector models like the one we use generate moderate welfare effects of trade liberalization. Implementing many sectors that use other sectors' output as intermediate inputs in their own production process magnifies welfare effects substantially - in Costinot and Rodriguez-Clare (2014) on average by a factor of six. We do not put too much emphasis on the level of welfare changes, but rather stress the heterogeneity across European regions triggering national and international migration. This establishes a main difference from the quantitative international trade literature (see Costinot and Rodriguez-Clare, 2014). As migration decisions are determined by relative welfare effects, we think that the model's prediction on migration flows is less sensitive to modelling decisions in this direction.

We build our analysis on recent work by Allen and Arkolakis (2014) employing an Armington trade model with perfect competition at the local level and heterogeneous goods across regions. Individuals are mobile across locations. Higher density causes both a positive production externality and a negative congestion externality ensuring stability and uniqueness of the migration equilibrium under certain parameter conditions. As trade is costly, geography matters for the attractiveness of locations. In the periphery, for example, distances to trading partners are larger on average implying higher price indices there compared to centrally-located regions. With a negative distance elasticity of trade flows exceeding unity, it is immediate (and well known from the gravity literature) that responses of trade flows to trade shocks are increasing in distance. This is the underlying force behind heterogeneous welfare effects of market integration across Europe and the implied migration pattern.

Our paper relates to a number of literatures. First, our paper adds to a recent and growing literature that extends quantitative trade models with factor mobility and exogenous local characteristics (e.g. Allen and Arkolakis, 2014, Bartelme, 2015, Behrens, Mion, Murata, Suedekum, 2017, Caliendo, Parro, Rossi-Hansberg and Sartre, 2014, Fajgelbaum and Redding, 2014, Monte, Redding and Rossi-Hansberg, 2015, and Redding, 2016). We apply this framework to the European context requiring inter-regional trade data that have not been used at this scale previously. This allows us to provide novel insights about the regional variation in welfare and migration effects in Europe.

Second, our paper contributes to the quantitative international trade literature fo- 
cussing on regional economic integration. In a recent study, Levchenko and Zhang (2012) apply a multi-sector Ricardian model to explore the welfare implications of European trade integration. Corcos, Del Gatto, Mion and Ottaviano (2012) examine welfare effects of intra-EU-15 trade integration in a monopolistic-competition model with endogenous markups. Apart from building on a different methodological framework, our work deviates as we focus at heterogeneous implications at a more disaggregated regional level and accounting for both inter-regional and international migration flows.

Third, we contribute to the debate on the economic consequences of a withdrawal of the United Kingdom from the European Union. To the best of our knowledge, we are only aware of one paper by Dhingra et al. (2016) quantifying welfare effects of the Brexit. In contrast to their paper, our approach allows us to highlight welfare changes at the regional level within the UK and derive migration responses.

The paper is organized as follows. We first introduce the model in section 2 . Section 3 discusses quantification and the data we use. We discuss counterfactuals in section 4 before offering concluding remarks in section 5

\section{A quantitative spatial model}

Setup. Consider a world with a continuum of locations $i \in S$ inhabited by $\bar{L}$ mobile workers 11 Each location produces one unique variety of a good under perfect competition like in Armington (1969) or Anderson (1979). Goods can be shipped to other locations at iceberg costs such that $T(i, s) \geq 1$ units have to be sent from $i$ for one unit to arrive in $s .^{2}$ Intra-regional trade costs, $T(i, i)$, are normalized to unity. Further, locations differ from each other with regard to productivity $A(i)$, amenities $u(i)$ and remoteness being determined by bilateral trade costs with their trade partners.

Workers have identical preferences over the continuum of varieties that can be substituted with each other with a constant elasticity of substitution $\sigma>1$. They also care about the utility derived from a local consumption amenity such that

$$
W(i)=\left(\int_{s \in S} q(s, i)^{\frac{\sigma-1}{\sigma}} d s\right)^{\frac{\sigma}{\sigma-1}} u(i)
$$

where $q(s, i)$ denotes consumption of the variety in location $i$ that is produced in $s !^{3}$ Welfare is increasing in both the quantity consumed and the number of differentiated

\footnotetext{
${ }^{1}$ The continuum of locations is only for generalization. Later in the analysis we will only rely on a discrete number of locations.

${ }^{2}$ We assume that the triangle inequality holds for any $T(i, s)$, i.e. $T(i, s)<T(i, k) T(k, s)$ for any $i, s$ and $k$.

${ }^{3}$ Allen and Arkolakis (2014) demonstrate that it is straightforward to introduce locational preferences into the utility function. This only affects the elasticity of amenities with respect to population as discussed below.
} 
varieties as well as in local amenities $u(i)$. Maximizing utility subject to income yields individual demand for a variety from $s$ in location $i$

$$
q(s, i)=w(i) p(s, i)^{-\sigma} P(i)^{\sigma-1}
$$

where $w(i)$ is the nominal wage paid in $i, p(s, i)$ denotes the consumer price in $i$ and $P(i)$ represents the price index. With labor as the only factor of production and provided that perfect competition on the product market equates prices to marginal costs, we obtain consumer prices as $p(s, i)=T(s, i) w(s) / A(s)$ and the price index

$$
P(i)=\left[\int_{s \in S} T(s, i)^{1-\sigma} A(s)^{\sigma-1} w(s)^{1-\sigma} d s\right]^{\frac{1}{1-\sigma}} .
$$

Local productivities and amenities are determined by an exogenous component, $\bar{A}(i)$ and $\bar{u}(i)$, and an endogenous part dependent on a location's population. The composite productivity level is given by

$$
A(i)=\bar{A}(i) L(i)^{\alpha}
$$

where $\alpha \geq 0$ represents the elasticity of productivity with respect to population density. This formalization is a short cut for agglomeration externalities like knowledge spillovers or labor-market pooling that increase firm productivity in location $i$ 出 In contrast, higher population density also causes congestion externalities rendering a location less attractive. Local amenities are defined as

$$
u(i)=\bar{u}(i) L(i)^{\beta}
$$

with $\beta \leq 0$ capturing the idea of a negative congestion externality.

Gravity. With these ingredients at hand, we are able to derive a gravity equation for bilateral trade flows between locations. Letting $X(i, s)$ be the value of shipments from $i$ to $s$, we have

$$
X(i, s)=\left(\frac{T(i, s) w(i)}{A(i) P(s)}\right)^{1-\sigma} w(s) L(s),
$$

where $1-\sigma$ is the trade elasticity of the CES demand system.

Equilibrium. In equilibrium, free mobility of individuals ensures that welfare is equalized across locations. Using insights from above, we can express welfare in location $i$ as a function of the location-specific amenity and real wages,

$$
W(i)=\frac{w(i)}{P(i)} u(i)
$$

Remote locations are characterized by a higher price index which has to be compensated by higher nominal wages and/ or higher amenities than in centrally-located places for

${ }^{4}$ See Combes and Gobillon (2015) for a recent overview of the empirical literature on agglomeration economies. 
$W(i)$ to be equalized across all $i \in S$.

Further, goods and factor markets need to clear. In equilibrium, the aggregate value of the good sold to all destinations is equal to total income, so

$$
w(i) L(i)=\int_{s \in S} X(i, s) d s \quad \forall i \in S
$$

Labor market clearing implies

$$
\int_{s \in S} L(s) d s=\bar{L}
$$

The Armington assumption ensures that all locations are specialized in the production of one unique differentiated variety, such that the equilibrium can be defined in aggregates. Based on the parameters $\alpha, \beta, \sigma, \bar{A}(i), T(i, s), \bar{u}(i)$, the general equilibrium can be described by a vector of six variables $\{w(i), L(i), P(i), X(i, s), u(i), A(i)\}_{i, s=1}^{S}$ and a scalar $W$. The equilibrium vector solves the following set of equations: welfare (7) is equalized across locations; goods markets clear, (8); bilateral sales, (6); price indices (3); amenities and productivities according to (5) and (4); and we finally apply labor-market clearing (9) to determine the scalar $W$.

Combining (6) and (7) with (8), we get

$$
W^{\sigma-1} L(i)^{1-\alpha(\sigma-1)} w(i)^{\sigma}=\int_{S} T(i, s)^{1-\sigma} \bar{A}(i)^{\sigma-1} \bar{u}(s)^{\sigma-1} L(s)^{1+\beta(\sigma-1)} w(s)^{\sigma} d s
$$

Second, (7) jointly with the price index (3) delivers

$$
W^{\sigma-1} L(i)^{\beta(1-\sigma)} w(i)^{1-\sigma}=\int_{S} T(s, i)^{1-\sigma} \bar{A}(s)^{\sigma-1} \bar{u}(i)^{\sigma-1} L(s)^{\alpha(\sigma-1)} w(s)^{1-\sigma} d s,
$$

where (4) and (5) have been substituted for composite productivities and amenities. Feeding the system of equations with information on bilateral trade costs, wages and population delivers solutions for exogenous productivities and amenities up to a constant with $W^{\sigma-1}$ as the eigenvalue of the system.5 Allen and Arkolakis (2014) show that there is a unique and stable equilibrium if $\alpha+\beta \leq 0$.

\section{Quantification}

Quantifying the model requires estimates for bilateral trade costs $T(i, s)$, exogenous productivities $\bar{A}(i)$ and exogenous amenities $\bar{u}(i)$. We discuss identification, data sources and results for these steps sequentially in the following two subsections. The basic geographic unit is the third level of administrative division called the Nomenclature of Territorial Units for Statistics (NUTS-3). NUTS-3 regions are jurisdictional entities whose average

\footnotetext{
${ }^{5}$ Allen and Arkolakis (2014) show how this system of equations can be translated into a single nonlinear equation system. We follow their procedure in solving and quantifying the model.
} 
population usually ranges between 150,000 and 800,000 people ${ }^{6}$ We choose the aggregation level of locations in a way to justify the assumption of no commuting and no spillovers between locations. The analysis contains information for $26 \mathrm{EU}$ countries plus Norway in 2010 which leaves us with 1,318 European regions.

\subsection{Parametrization of trade costs}

To the best of our knowledge, there is no data set that contains information on interregional trade flows between all European NUTS-3 regions. However, German authorities provide information on a subset of inter-regional trade flows comprising information on the annual volume of intra-German and European shipments (in metric tons) that went through German territory in 2010. The data come from the Forecast of Nationwide Transport Relations in Germany 2030 (Verkehrsverflechtungsprognose 2030, henceforth VVP) provided by the Clearing House of Transport Data at the Institute of Transport Research of the German Aerospace Center 7 The dataset allows us to differentiate by mode of transportation (road, rail, water) and by product category. We do not rely on transportation by mode, however, and aggregate shipments over all transport modes at the first level of the NST2007 classification 8

Table 1 provides an overview of the VVP-data coverage by comparing the reported aggregated trade volumes at the country level to those in COMTRADE.9 First, we observe that about 87 percent of trade flows refer to intra-German transactions that are not covered by COMTRADE. Trade of German regions with other European regions makes up about 9 percent leaving about 4 percent of the overall volume as transit shipments. Second, we aggregate up trade volumes between regions in Germany and the 28 European countries that are member of the European Union (EU) plus Iceland, Liechtenstein, Norway and Switzerland that are members of the European Free Trade Association (EFTA). COMTRADE covers 98 percent of the volumes reported in the VVP-dataset for 2010 indicating high quality of the regional trade data we use. With regard to bilateral trade flows between the set of European economies without Germany, however, the VVP-dataset covers only 12 percent of the COMTRADE volume. This makes sense as VVP only reports those trade flows between European countries that transit through Germany. In the case of Spain and France, for instance, it is hard to imagine that goods should be shipped via Germany. If there is a systematically lower coverage of trade flows for more

\footnotetext{
${ }^{6}$ The principles and characteristics of the nomenclature of territorial units for statistics are available at http://ec.europa.eu/eurostat/web/nuts/principles-and-characteristics.

${ }^{7}$ The data can be accessed via http://daten.clearingstelle-verkehr.de/276/.

${ }^{8} \mathrm{NST}$ is the abbreviation for Nomenclature uniforme des marchandises pour les statistiques de transport. This system represents a standard classification for transport statistics for goods transported by road, rail, inland waterways and sea (maritime) at the European level since 2008 and is based on the classifications of products by activity (CPA).

${ }^{9}$ Notice that COMTRADE data are only available at the country level, but contain both volume and value information at the product level.
} 
Table 1: Aggregate trade volumes: COMTRADE vs. VVP

\begin{tabular}{lcc} 
& COMTRADE & VVP \\
\hline Germany - Rest of Europe & 279.39 & 285.49 \\
Rest of Europe - Rest of Europe & $1,175.18$ & 145.30 \\
Germany - Germany & - & $2,854.82$ \\
\hline
\end{tabular}

Notes: This table reports aggregate trade volumes in million metric tons. Column (2) reveals data from COMTRADE. Column (3) presents trade volumes from the Forecast of Nationwide Transport Relations in Germany 2030 (VVP). Both columns refer to the year 2010.

distant locations, estimates of distance elasticities could be biased. We therefore focus on inter-regional trade flows where a German region is either an exporter or an importer. We relegate further details on this dataset to Appendix A.

As the regional trade data only contain information on volumes, we need to obtain values to apply the gravity equation. To this end, we define the ratio of values and quantities based on trade data from COMTRADE for the same set of countries and 2digit product categories in 2010 to compute trade values. With this information at hand, we run a standard gravity regression to uncover the distance elasticity of trade flows. We follow the standard procedure in the gravity literature (see, e.g., Head and Mayer, 2014, for an overview) by estimating (6) with importer and exporter fixed effects to control for multilateral resistance. We proxy bilateral trade costs by distance according to

$$
T(i, s)=\operatorname{dist}(i, s)^{\theta} \tilde{\epsilon}(i, s)
$$

where $\tilde{\epsilon}(i, s)$ is the error term. GIS software delivers Euclidian distances $\operatorname{dist}(i, s)$ between the centroids of locations $i$ and $s$, so we end up with a $1,318 \times 1,318$ matrix. Loglinearizing (6) and substituting for the parametrization of trade costs yields the following gravity equation for the value of bilateral trade flows from $i$ to $s$ :

$$
\log X(i, s)=\delta(i)+\gamma(s)-(\sigma-1) \theta \log \operatorname{dist}(i, s)+\log \epsilon(i, s)
$$

where $\delta(i)$ and $\gamma(s)$ are exporter and importer fixed effects that control for wages, productivity, population and the CES price index 10 Further, $\log \epsilon(i, s)=(1-\sigma) \log \tilde{\epsilon}(i, s)$.

Table 2 summarizes the regression output. Columns (2) and (3) build on bilateral trade values as the dependent variable where the latter specification adds commonly-used non-geographic covariates like language, contiguity and border. Following Nitsch and Wolf (2013), we also explore results for volumes instead of values as the dependent variable. Although this deviates from the theoretical model, it can be argued that trade values are proportional to trade volumes so the results are insightful for robustness reasons. Further,

\footnotetext{
${ }^{10}$ As the data distinguishes between product groups, we add product fixed effects in the estimation.
} 
Table 2: Estimated Distance Elasticities

\begin{tabular}{|c|c|c|c|c|}
\hline & \multicolumn{2}{|c|}{ Values } & \multicolumn{2}{|c|}{ Volumes } \\
\hline & (1) & $(2)$ & (3) & $(4)$ \\
\hline $\log ($ distance $)$ & $\begin{array}{c}-1.21^{* * *} \\
-0.002\end{array}$ & $\begin{array}{c}-1.15^{* * *} \\
-0.002\end{array}$ & $\begin{array}{c}-1.24^{* * *} \\
-0.002\end{array}$ & $\begin{array}{c}-1.17^{* * *} \\
-0.002\end{array}$ \\
\hline language & & $\begin{array}{c}0.04 \\
-0.021\end{array}$ & & $\begin{array}{c}0.02 \\
-0.019\end{array}$ \\
\hline contiguity & & $\begin{array}{c}-0.14^{* * *} \\
-0.008\end{array}$ & & $\begin{array}{c}-0.17^{* * *} \\
-0.008\end{array}$ \\
\hline border & & $\begin{array}{c}-1.05^{* * *} \\
-0.011\end{array}$ & & $\begin{array}{c}-1.18^{* * *} \\
-0.01\end{array}$ \\
\hline Constant & $\begin{array}{c}18.50^{* * *} \\
-0.03\end{array}$ & $\begin{array}{c}20.20^{* * *} \\
-0.043\end{array}$ & $\begin{array}{l}4.32^{* * *} \\
-0.026\end{array}$ & $\begin{array}{l}6.30^{* * *} \\
-0.038\end{array}$ \\
\hline Exporter FE & Yes & Yes & Yes & Yes \\
\hline Importer FE & Yes & Yes & Yes & Yes \\
\hline Product FE & Yes & Yes & Yes & Yes \\
\hline Observations & $1,772,302$ & $1,772,302$ & $2,228,320$ & $2,228,320$ \\
\hline$R^{2}$ & 0.71 & 0.72 & 0.37 & 0.38 \\
\hline
\end{tabular}

Notes: Robust standard errors in parentheses. ${ }^{* * *},{ }^{* *},{ }^{*}$ denote significance at the 1 , 5-, and 10-percent level, respectively. Columns (1) and (2) are based on total trade values. In columns (3) and (4) we use trade volumes in tons per 2-digit product group from VVP as the dependent variable. In all specifications, we account for exporter, importer and product fixed effects.

exporter and product-specific dummy variables account for the exporter- and productspecific price per ton that converts volume of exports into values.

The estimated coefficients on log distance are remarkably similar and range between -1.15 and -1.24 , independent of using values or volumes. Moreover, the estimates are all statistically different from zero at the 1-percent level. Comparing our findings to those in the gravity literature establishes further credibility. Head and Mayer (2014) summarize that estimates of the trade-distance elasticity parameter in typical gravity equations cluster around -1.1 with a standard deviation of 0.41 .

\subsection{Identifying location fundamentals}

A second piece of information that is unobservable from data, but required for quantification of the model, are values of exogenous productivities $\bar{A}(i)$ and amenities $\bar{u}(i)$. To uncover these model parameters, we feed estimated trade costs together with information on population $L(i)$ and wages $w(i)$ (proxied by GDP per capita) into (10) and (11). Both variables are provided by Eurostat at the NUTS-3 regional level. We divide total population of each region in 2010 by the area of that region and normalize both the population 
density and wages to have a mean of one 11

We use the structure of the model to solve for the overall productivity $A(i)$ and amenity $u(i)$ level. Then we use (5) and (4) to identify $\bar{A}(i)$ and amenity $\bar{u}(i)$ for all possible combinations of $\alpha$ and $\beta$. In the baseline, we follow Allen and Arkolakis (2014) in choosing $\alpha=0.1$ and $\beta=-0.3$. These values can be justified as follows: Rosenthal and Strange (2004) highlight empirical evidence for positive productivity externalities with respect to population density of close to 10 percent. The value for $\beta$ can be retrieved from expenditure share data on housing. Allen and Arkolakis (2014) demonstrate that the model is isomorphic to a class of theories where workers spend a constant share $\delta$ of their income on differentiated goods and $1-\delta$ on local non-tradable goods (e.g. housing) with $\beta=\delta /(1-\delta)$. According to Eurostat, average expenditure on housing amounted to 24.2 percent in the EU (28 countries) in 2010 justifying the chosen value for $\beta \mathbb{1}^{12}$ In the baseline scenario, we choose $\sigma=9$, which is in line with the preferred trade elasticity of 8 in Eaton and Kortum (2002). As a sensitivity check, we use $\sigma=5$ implying a trade elasticity of 4 as suggested by Simonovska and Waugh (2014). Additionally, we calculate the model for a wider range of spillover parameters for sensitivity.

Figure 1 illustrates the distribution of exogenous productivities (Panel (a)) and amenities (Panel (b)) across European regions in the baseline case. Locations with high percapita income have higher values of exogenous productivity, like in central Europe and Scandinavia. Eastern Europe features comparably low levels of exogenous productivity. The picture changes when we take a look at exogenous amenities. Technically speaking, the model predicts higher values of $\bar{u}(i)$ for locations with lower income to rationalize the location choice of people living there. This is why Eastern European regions show darker colors (i.e. higher values) of $\bar{u}(i)$ in Panel (b) of Figure 1 .

Combining our estimates for trade costs, exogenous productivities and amenities with wages, it is instructive to take a look at the implied price index in each location. Figure 2 illustrates the resulting geographic variation. The figure shows that our specification of trade costs as a constant elasticity function of distance leads to concentric circles around the geographic center of Europe. Intuitively, remote locations like Greece, Portugal or Finland have the highest price index so we can use $P(i)$ as a proxy for remoteness below.

\footnotetext{
${ }^{11}$ See Allen and Arkolakis (2014) for details.

${ }^{12}$ We use information on the final consumption expenditure of households by consumption purpose (COICOP 3 digit) from Eurostat with the code: nama_10_co3_p3.
} 


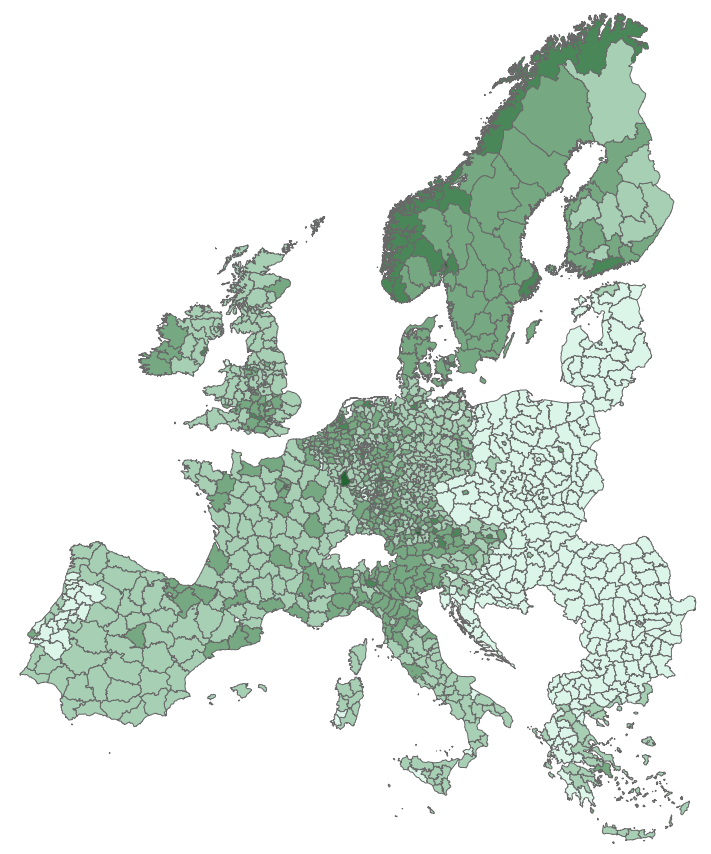

(a) Exogenous productivities

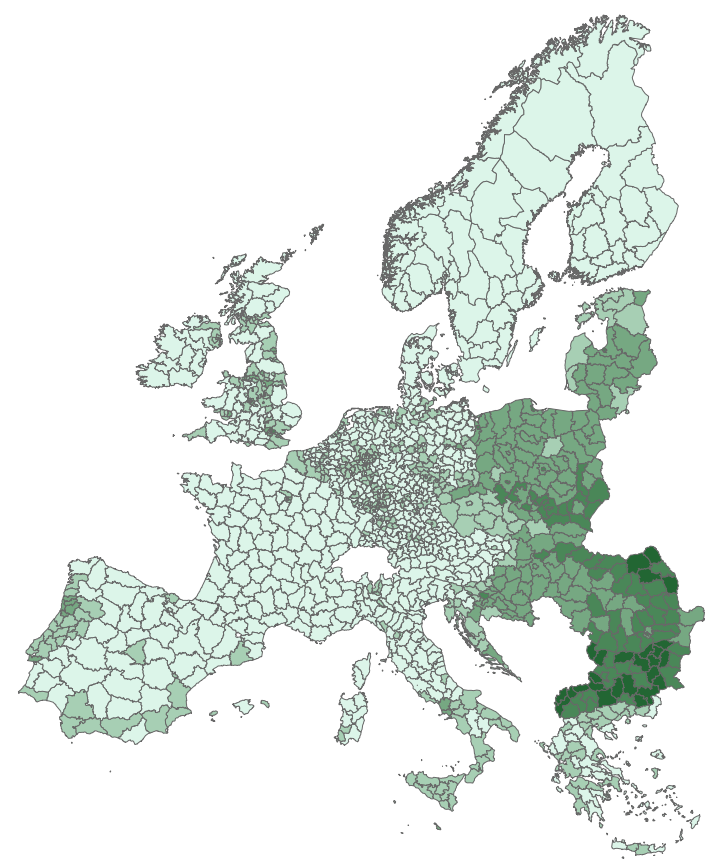

(b) Exogenous amenities

Figure 1: Estimated eXogenous PRoductivities And AMenities

Notes: This figure plots the exogenous productivity $\bar{A}(i)$ and amenity $\bar{u}(i)$ for $\alpha=0.1$ and $\tilde{\beta}=-0.3$. A darker shading indicates higher values. 


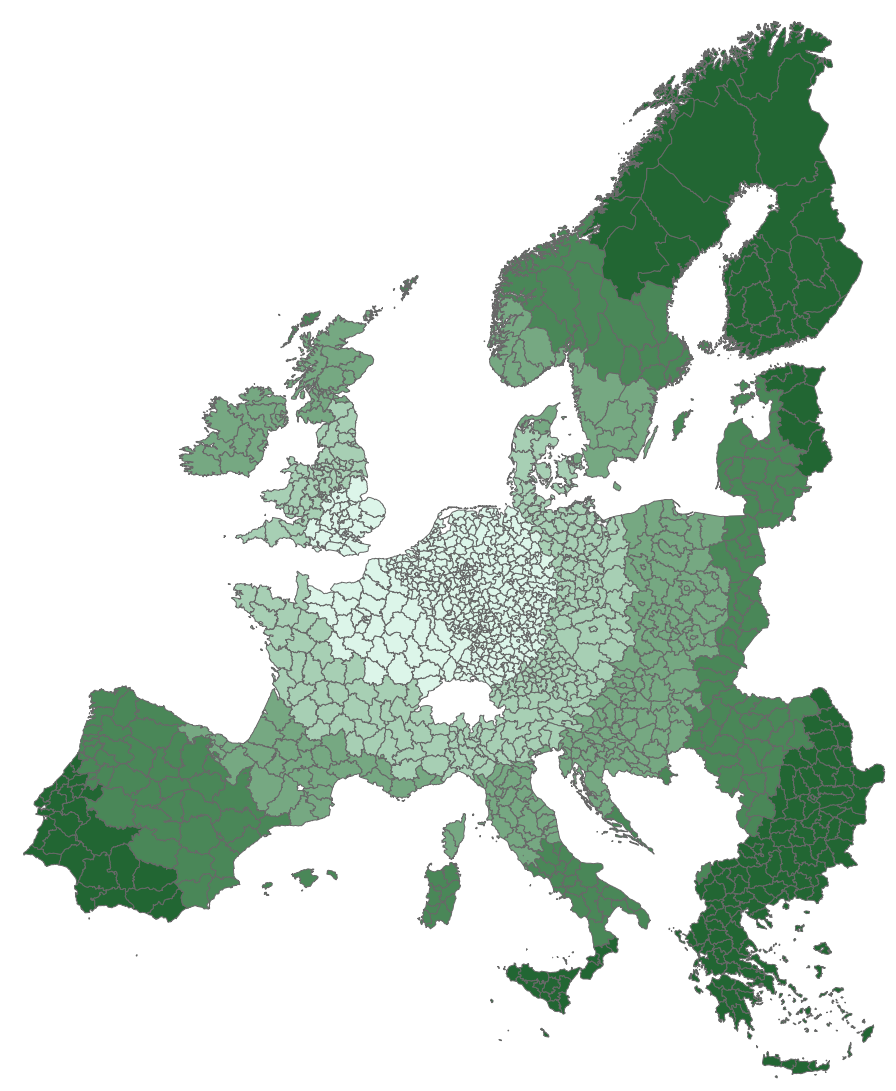

Figure 2: Estimated Price Index

Notes: This figure plots the estimated price index $P(i)$ for $\alpha=0.1$ and $\beta=-0.3$. A darker shading indicates higher values.

\section{Counterfactuals}

Based on the fundamentals of the model, we proceed by studying two major events of European integration. First, we withdraw the market integration steps since the foundation of the European Community in 1957 including the establishment of the Common and the Single Market. Second, we look ahead in time and evaluate different scenarios for the Brexit. Apart from overall effects on welfare and migration, we are particularly interested in the differences in welfare responses across regions and their implied migration flows that shape the economic landscape of Europe in the long run. As we have quantified the model based on data from 2010, we evaluate previous episodes of trade liberalization by simulating a situation prior to the respective reduction in trade costs. This means, we raise trade barriers to the level before the European Community was founded and compare this outcome to the status quo. Moreover, we keep the number of countries fixed. One might object that it is unnecessary to "replicate" the past as we can simply take a look at historical data. The rigidity of the model, however, allows us to abstract from other factors that have shaped the development of the local economy over time (e.g. technological change, population growth or changes in preferences) and simply focus on the implications 
of changes in trade costs. With regard to the Brexit, of course, we make statements about a trade shock that lies ahead of the baseline year 2010 .

It is noteworthy that changes of trade costs have a specific flavor in our model. Trade integration is associated with lower barriers across national borders while bilateral trade costs do not change within countries. This is one of the novel aspects of quantitative spatial models allowing us to also study differential responses of border regions compared to non-border regions. We proceed in the standard way by using the estimated primitives of the model jointly with counterfactual trade costs to solve for wages and population density. Relating these values to observed data on wages and population in 2010 allows us to compute welfare changes and implied migration flows as a response to these hypothetical trade shocks.

\subsection{Reversing the Common and Single Market}

The introduction of the Common Market in 1957 and the Single Market in 1992 were two important steps towards a reduction of trade barriers within the European Union. Levchenko and Zhang (2012) have estimated that trade costs within Western Europe were about 45 percent higher in the 1960s compared to the 2000s. As trade barriers were substantially reduced in the 1950s already, Levchenko and Zhang (2012) admit that their estimate understates the overall difference in trade costs from before European integration to the present. Nevertheless, we use these estimates as a helpful point of departure and suppose that trade costs in the 1950s were about 60 percent higher than in 201013 Then the model informs us about changes in welfare and population density. Of course, we ignore changes in exogenous productivities and amenities over time and only let changes in trade barriers drive welfare changes and migration according to the model.

We simulate the model for three different mobility scenarios: no labor mobility, intranational labor mobility, and international (within Europe) labor mobility. Table 3 reports welfare changes by country in columns (1)-(3) in the absence of labor mobility and implied changes in population in columns (4)-(6) when workers can freely choose their place of residence. Note that the average welfare changes in column (1) are realized for all regions within a country when labor is allowed to move within national boundaries. In our benchmark specification, the model predicts an average welfare loss of 1.1 percent. However, the regional differences are enormous. Looking at average welfare changes by country, it is immediate that countries that are located in the periphery of Europe lose most while those in the center lose least. To name a few examples, Greece (-3.1 percent), Finland (-2.8 percent) or Portugal (-2.7 percent) lose more than Belgium (-0.8 percent), Germany (-0.8 percent) or France (-0.9 percent). At the regional level, these disparities become even

\footnotetext{
${ }^{13}$ We have also derived results for trade costs changes of 50 percent and 100 percent, respectively, to assess the sensitivity of results. The overall welfare change increases by a factor of 1.8 when we increase trade costs changes from 50 to 100 percent. The results are available from the authors upon request.
} 
Table 3: WeLfARE CHANGE AND IMPLIED MIGRATION FLOWS

\begin{tabular}{|c|c|c|c|c|c|c|}
\hline \multirow[b]{2}{*}{ Country } & \multicolumn{3}{|c|}{ No mobility } & \multicolumn{3}{|c|}{ International mobility } \\
\hline & $\Delta W(i)$ & $\min$ & $\max$ & $\Delta L(i)$ & $\min$ & $\max$ \\
\hline Austria & -1.44 & -1.57 & -1.07 & -0.79 & -1.39 & 0.09 \\
\hline Belgium & -0.78 & -0.79 & -0.77 & 0.97 & 0.92 & 1.00 \\
\hline Bulgaria & -2.78 & -3.07 & -2.49 & -5.14 & -5.83 & -4.14 \\
\hline Croatia & -1.74 & -2.14 & -1.58 & -2.06 & -3.11 & -1.44 \\
\hline Czech Republic & -1.32 & -1.60 & -1.11 & -0.76 & -1.50 & -0.02 \\
\hline Denmark & -1.42 & -1.52 & -1.24 & -0.88 & -1.27 & -0.43 \\
\hline Estonia & -2.69 & -2.83 & -2.50 & -4.73 & -5.19 & -4.20 \\
\hline Finland & -2.84 & -3.70 & -2.43 & -5.70 & -7.76 & -4.00 \\
\hline France & -0.90 & -1.57 & -0.73 & 0.03 & -1.41 & 1.12 \\
\hline Germany & -0.76 & -0.99 & -0.59 & 0.96 & 0.31 & 1.53 \\
\hline Greece & -3.13 & -3.82 & -2.72 & -5.89 & -8.03 & -4.81 \\
\hline Hungary & -1.84 & -2.09 & -1.62 & -2.26 & -2.98 & -1.55 \\
\hline Ireland & -1.52 & -1.76 & -1.48 & -1.62 & -2.02 & -1.18 \\
\hline Italy & -1.69 & -2.75 & -1.17 & -2.04 & -4.90 & -0.20 \\
\hline Latvia & -2.42 & -2.64 & -2.23 & -4.07 & -4.62 & -3.40 \\
\hline Lithuania & -2.27 & -2.46 & -2.10 & -3.52 & -4.09 & -3.02 \\
\hline Luxembourg & -0.81 & -0.80 & -0.80 & 0.90 & 0.90 & 0.90 \\
\hline Netherlands & -0.83 & -0.93 & -0.76 & 0.80 & 0.50 & 1.01 \\
\hline Norway & -1.97 & -3.97 & -1.65 & -3.57 & -8.53 & -1.69 \\
\hline Poland & -1.70 & -2.14 & -1.34 & -1.90 & -3.12 & -0.74 \\
\hline Portugal & -2.67 & -3.02 & -2.36 & -4.63 & -5.70 & -3.76 \\
\hline Romania & -2.71 & -3.00 & -2.17 & -4.37 & -5.63 & -3.18 \\
\hline Slovakia & -1.72 & -1.97 & -1.58 & -1.96 & -2.62 & -1.44 \\
\hline Slovenia & -1.56 & -1.61 & -1.47 & -1.36 & -1.54 & -1.11 \\
\hline Spain & -2.75 & -3.03 & -1.75 & -3.51 & -5.71 & -1.96 \\
\hline Sweden & -1.99 & -3.35 & -1.52 & -3.12 & -6.73 & -1.28 \\
\hline United Kingdom & -0.96 & -1.57 & -0.75 & 0.19 & -1.45 & 1.04 \\
\hline
\end{tabular}

Note: This table reports percentage change in welfare and population in response to a 60 percent increase of trade costs between European countries. Columns (1)-(3) assume no labor mobility and report average welfare changes per country as well as minimum and maximum values across regions. Column (4) reports the percentage change in population when we allow for labor to move freely across all locations. Columns (5) and (6) show the minimum and maximum population change in a region per country. 
more pronounced. The largest loss is observed in Greece with nearly 4 percent while the region with the lowest welfare loss of -0.59 percent is located in Germany - in the centre of Europe.

If we allow people to migrate to those places that offer the highest welfare level, we observe from columns (4)-(6) that migration would take place from the periphery to the core. There are only 6 out of 27 countries that experience immigration, namely Belgium, Germany, France, Luxembourg, the Netherlands and the United Kingdom. Greece is predicted to lose nearly 6 percent of its population as a response to this trade shock in the long run, some Greek regions even up to 8 percent. Corresponding to the welfare results, the region with the largest inflow of people can be found in Germany where the population is predicted to increase by 1.53 percent. Translating these figures to absolute migration flows delivers a value of 8.12 million individuals or 1.6 percent of the European population that would change their region of residence as a response to this trade shock.

To better understand the importance of location fundamentals for the change in welfare, we derive conditional correlations from a simple regression of the form

$$
\Delta W(i)=\beta_{0}+\beta_{1} L_{0}(i)+\beta_{2} \bar{A}(i)+\beta_{3} \bar{u}(i)+\beta_{4} P_{0}(i)+\beta_{5} \text { border }+\epsilon(i) .
$$

$\Delta W(i)$ denotes the percentage change in welfare for the scenario without labor mobility, $L_{0}(i)$ and $P_{0}(i)$ reflect population density and the price index in location $i$ prior to the change in trade costs. The latter can be interpreted as a measure of remoteness as regions located in the periphery are characterized by higher average trade costs and thus higher values of $P_{0}(i)$. Exogenous productivities, $\bar{A}(i)$, exogenous amenities, $\bar{u}(i)$, and a dummy variable equal to one for all regions adjacent to a national border complete the list of covariates. $\epsilon(i)$ reflects a stochastic error term. We run two versions of the above specification, one without and one with country fixed effects, to explore the relevance of unobserved country characteristics. It is immediate from Table 4 that remoteness, as proxied by the price index, turns out to play the most important role. Also the border dummy turns out significant. In contrast, the estimates for initial population density or exogenous productivity are not statistically different from zero. As $\Delta W(i)$ is negative for all locations, we can infer that a higher initial price index leads to stronger negative responses to increases in trade costs. border exerts the same impact qualitatively.

$P_{0}(i)$ and border represent measures for remoteness at the European and the national level, respectively, so the estimation results indicate that regions are affected differently by a common trade cost shock. Although trade barriers are only raised at national borders in this counterfactual exercise, regions in the European periphery (those with a higher price index) lose more if the trade elasticity exceeds minus one. This is a standard insight from international trade theory (see, e.g. Anderson and van Wincoop, 2003). A similar argument can be made with respect to a region's location within a country. If located 
Table 4: Welfare Change AND LOCATion ChaRACTERISTICS

\begin{tabular}{lcc} 
& $(1)$ & $(2)$ \\
\hline$L_{0}(i)$ & 0.027 & -0.002 \\
& $(0.027)$ & $(0.007)$ \\
$\bar{A}(i)$ & 0.214 & 0.070 \\
& $(0.159)$ & $(0.054)$ \\
$\bar{u}(i)$ & $-0.330^{* * *}$ & -0.031 \\
& $(0.186)$ & $(0.058)$ \\
$P_{0}(i)$ & $-3.330^{* * *}$ & $-3.816^{* * *}$ \\
& $(1.06)$ & $(0.171)$ \\
border & $-0.414^{* * *}$ & $-0.069^{* * *}$ \\
& $(0.13)$ & $(0.024)$ \\
Country FE & No & Yes \\
\hline$R^{2}$ & 0.85 & 0.98 \\
Observations & 1,318 & 1,318 \\
\hline
\end{tabular}

Notes: Clustered standard errors in parentheses. ${ }^{* * *},{ }^{* *},{ }^{*}$ denote significance at the 1-, 5-, and 10percent level, respectively. This table reports OLS estimates of welfare changes in percent, $\Delta W(i)$, without labor mobility on a region's characteristics.

close to a national border, raising trade barriers at the border increases the remoteness of this location relative to other non-border locations in the same country. This is why, controlling for overall remoteness through $P_{0}(i)$, border comes out with a negative sign.

To get a feeling for the sensitivity of the results, we repeat the counterfactual exercise for alternative values of $\sigma, \alpha$, and $\beta$ and compute associated welfare changes and implied overall migration flows in millions and in percent of the European population. We compare $\sigma=9$, which is in line with the preferred trade elasticity of 8 in Eaton and Kortum (2002), with $\sigma=5$ implying a trade elasticity of 4 as suggested by Simonovska and Waugh (2014). Further, we double the productivity elasticity $\alpha$ and reduce the congestion elasticity $\beta$ to -0.6. As shown by Allen and Arkolakis (2014), the model can be straightforwardly extended to account for heterogeneous locational preferences of workers where $\beta=\beta_{0}-1 / \theta$. Setting the Frechet shape parameter $\theta=3$, as suggested by Bryan and Morten (2014) and used in Redding (2016), and keeping the baseline congestion elasticity at $\beta_{0}=-0.3$ we arrive at a value of approximately -0.6.

Table 5 provides an overview of results. We observe that reducing $\sigma$ from a value of 9 to 5 roughly doubles welfare responses - from our baseline scenario of -1.11 percent (row 1) to -2.08 percent (row 5). Intuitively, a lower elasticity of substitution implies that consumers do not respond as elastically to changes in relative prices by substituting expensive goods. As a consequence, higher trade costs lead to larger changes in the overall price index and thus in welfare. Notice, however, that the ranking of welfare losses across regions is not affected. Migration flows respond less sensitively to reductions in $\sigma$ than 
Table 5: Sensitivity: Welfare and European migration

\begin{tabular}{cccccc}
$\sigma$ & $\alpha$ & $\beta$ & $\begin{array}{c}\text { Welfare change } \\
\text { (in percent) }\end{array}$ & $\begin{array}{c}\text { Migrants } \\
\text { (in millions) }\end{array}$ & $\begin{array}{c}\text { Migrants } \\
\text { (in percent) }\end{array}$ \\
\hline 9 & 0.1 & -0.3 & -1.11 & 8.12 & 1.60 \\
9 & 0.1 & -0.6 & -1.16 & 4.17 & 0.82 \\
9 & 0.2 & -0.3 & -1.06 & 11.30 & 2.23 \\
9 & 0.2 & -0.6 & -1.15 & 4.88 & 0.96 \\
5 & 0.1 & -0.3 & -2.08 & 11.41 & 2.25 \\
5 & 0.1 & -0.6 & -2.18 & 6.64 & 1.31 \\
5 & 0.2 & -0.3 & -2.00 & 14.18 & 2.80 \\
5 & 0.2 & -0.6 & -2.15 & 7.49 & 1.48 \\
\hline
\end{tabular}

Note: This table reports welfare changes and migration (in millions and in percent of the total population) for different parameter values of $\sigma, \alpha$ and $\beta$ when trade costs are increased by 60 percent between countries.

welfare. Nevertheless, overall migration is predicted to rise by around 40 percent compared to the benchmark.

Accounting for locational preferences (higher value of $\beta$ ) or a higher productivity elasticity $\alpha$ does not lead to major changes in welfare responses. However, migration is naturally affected a lot. If individuals have preferences to reside in certain locations, they are more reluctant to move in response to exogenous shocks. Thus raising $\beta$ nearly halves migration flows to about 4 million individuals. The opposite happens, of course, if the positive agglomeration externality rises. In that case, wages respond more elastically to every additional immigrant rendering the location more attractive for other individuals from other locations. Comparing rows 1 and 3 reveals that overall European migration increases by about 40 percent. Interestingly, if we combine both effects (as shown in row 4), migration remains substantially lower than in the baseline scenario.

As regions are affected to different extents, we finally examine how an increase in trade barriers at national borders affect the distribution of local GDP. Table 6 summarizes three different measures of inequality, namely variance, Gini-index, and Theil-index, before the trade cost shock and after the shock with intranational labor mobility and international labor mobility. We observe that the inequality measures increase by 0.54 percent, 0.02 percent and 0.11 percent, respectively, if workers can freely migrate within national borders. Allowing for international migration raises inequality by a factor of $4-8$. The variance is now predicted to increase by 2.2 percent, the Gini-index rises by 0.16 percent while the Theil-index goes up by 0.4 percent. In sum, the numbers suggest that trade integration in Europe has led to a more equal distribution of economic activity across regions. 
Table 6: Reversing European integration: Inequality of LOCAL GDP

\begin{tabular}{|c|c|c|c|c|c|c|}
\hline & Var & $\Delta \operatorname{Var}(\%)$ & Gini & $\Delta G i n i(\%)$ & Theil & $\Delta$ Theil $(\%)$ \\
\hline before the shock & 49.75 & & 0.81 & & 1.71 & \\
\hline $\begin{array}{l}\text { after the shock, } \\
\text { intranational mobility }\end{array}$ & 50.02 & 0.54 & 0.81 & 0.02 & 1.71 & 0.11 \\
\hline $\begin{array}{l}\text { after the shock, } \\
\text { international mobility }\end{array}$ & 50.84 & 2.18 & 0.81 & 0.16 & 1.72 & 0.42 \\
\hline
\end{tabular}

Note: This table reports the level and percentage changes of inequality statistics of local gross domestic product (GDP).

\subsection{The Brexit}

Turning from a historical event to the present, we use the model to study the implications of the Brexit for regional welfare and migration in both the UK and continental Europe. In 2013, Britain's prime minister David Cameron announced to hold a referendum about membership in the European Union. Three years later, 51.9 percent of voters supported a withdrawal from the EU inducing prime minister Cameron to step back. $\sqrt{14}$ While the conditions of Brexit will be negotiated in the near future, it is expected that UK's access to the Single Market will be restricted implying higher trade frictions between the UK and the rest of the EU.

We consider two scenarios of how trade costs change after the Brexit following Dhingra et al. (2016). In the optimistic scenario we assume that the UK would face one quarter of the tariff-equivalent of non-tariff barriers between the USA and the EU. Berden et al. (2013) have estimated this value at 14.7 percent. This delivers a total trade cost increase of $\Delta T(i, s)_{E U-U K}=0.25 \times N T B_{E U-U S A}=0.25 \times 14.7=3.67$ percent.

The pessimistic scenario presumes that international trade takes place under the regulations of the World Trade Organization. Both the UK and the EU will then apply their most favoured nation tariff (MFN) on imports. Adding 75 percent of the tariff equivalent of non-tariff barriers between the EU and the USA, we get a total trade cost increase of $\Delta T(i, s)_{E U-U K}=0.75 \times N T B_{E U-U S A}+M F N_{E U-U K}=0.75 \times 14.7+((3.09+2.6) / 2)=$ 13.87 percent. It is noteworthy that we raise trade costs between regions located in the UK and those in other EU countries while intranational trade costs remain identical everywhere.

If we allow labor mobility within the UK and within the rest of Europe separately, the model predicts that welfare in the UK declines by 0.23 percent in the pessimistic scenario and by 0.06 percent in the optimistic case. Continental Europe is affected less with changes of -0.09 percent and -0.03 percent, respectively. If we reduce the elasticity of substitution to $\sigma=5$, the welfare effects roughly double. More precisely, welfare is predicted to decline in the UK by 0.44 percent and 0.12 percent in the pessimistic and

\footnotetext{
${ }^{14}$ See Dhingra et al. (2016) for a more detailed exposition.
} 
optimistic case, respectively. The figures for continental Europe are 0.18 percent and 0.05 percent. These numbers are fairly small, but in line with single-sector trade models predicting only moderate welfare changes in response to trade costs 15 Dhingra et al. (2016) find welfare losses of 1.28 percent and 2.61 percent in the pessimistic and the optimistic scenario, respectively, employing a multi-sector Armington trade model à la Costinot and Rodriguez-Clare (2014). While it is well understood that introducing multiple sectors and intermediate goods magnifies welfare effects, our focus is on heterogeneous effects across regions and their implied migration consequences. Moreover, in Dhingra et al. (2016) the change in welfare is mainly due to the assumption that intra-EU trade barriers decline by 5.7-10.5 percent in the next decade. If we allowed for this effect in addition, our welfare responses would increase by a factor of two in the pessimistic and five in the optimistic scenario.

Panel (a) of Figure 3 offers a graphical illustration of changes in welfare in the pessimistic scenario when labor is assumed to be immobile. This would be the initial shock and is instructive to evaluate to what extent locations are affected differently. We observe that Scotland experiences the largest initial welfare loss of about -0.3 to -0.38 percent while welfare declines by only -0.17 to -0.21 percent in the London area. In the rest of Europe, regions in the vicinity of the UK like Belgium or the Netherlands face the lowest welfare losses of about 0.02 percent. Similar effects occur in Ireland.

Panel (b) of Figure 3 shows percentage changes of population based on free mobility within the UK and within continental Europe (plus Ireland), respectively. Corresponding to the welfare results, Scotland experiences the largest decline in population of up to - 0.88 percent. In contrast, the south of England gains up to 0.27 percent. Intuitively, Scotland suffers from its remote position relative to the geographic center of Europe and there are no regions in the North that could serve as substitute trade partners. Looking at migration responses in continental Europe, it is astonishing that a similar pattern leads to higher densities in the core (like Belgium, the Netherlands, parts of Germany and France) at the expense of the periphery. Population is predicted to increase by about 0.16 to 0.5 percent in this greater area.

As the above results relate only to the scenario where labor can migrate within the UK or within the rest of Europe, we are also interested in migration patterns with free mobility across Europe. We therefore compute migration flows both in total and as a share of the population in the UK and in the rest of Europe, respectively, rather than relative to each NUTS3-region. We observe from Table 7 that total migration within the UK amounts to about 52,000 individuals or 0.08 percent of the population if we consider the pessimistic scenario with a baseline value of $\sigma=9$ (row 1 ). The corresponding figures for the $\mathrm{EU}$ are 451,000 or 0.1 percent of the population. In sum, the Brexit causes migration

\footnotetext{
${ }^{15}$ See the survey by Costinot and Rodriguez-Clare (2014).
} 


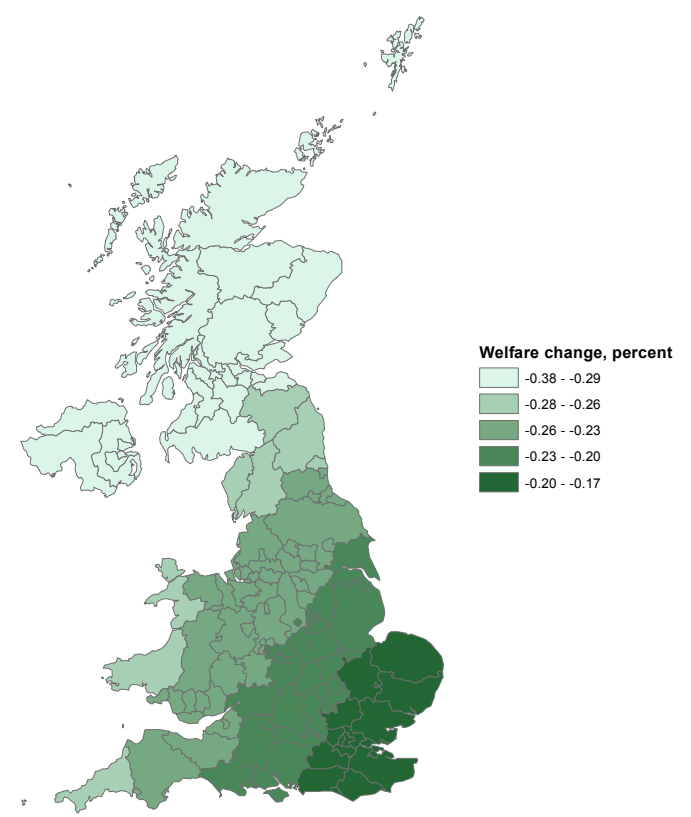

(a) Welfare

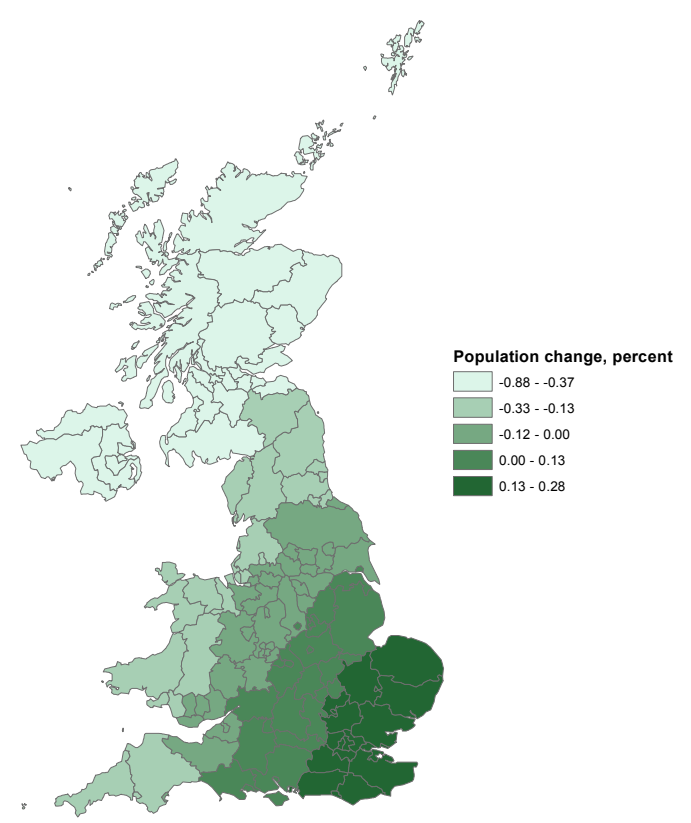

(b) Population

Figure 3: Estimated Welfare and POPUlation CHANGES IN PERCENT

Notes: This figure plots the percentage change in welfare in Panel (a) and population density in Panel (b) after the Brexit in the pessimistic scenario where trade costs between the UK and the EU increase by 13.9 percent for EU-UK trade flows.

of about 500,000 individuals. If migration remains free across UK-EU boundaries, the model predicts that 366,000 individuals would relocate to another region. As the UK experiences a larger welfare loss than the EU, all relocation takes place across the Channel to settle in the EU. As the Brexit affects regions heterogeneously, as shown above, an additional 348,000 Europeans change location within the other European countries - which 
Table 7: Sensitivity: Migration flows

UK EU

\begin{tabular}{|c|c|c|c|c|c|}
\hline Scenario & $\sigma$ & in thousands & in percent & in thousands & in percent \\
\hline \multirow{6}{*}{ Pessimistic } & & \multicolumn{4}{|c|}{ Within } \\
\hline & 9 & 52.64 & 0.08 & 451.19 & 0.10 \\
\hline & 5 & 75.45 & 0.12 & 634.00 & 0.14 \\
\hline & & \multicolumn{4}{|c|}{ Free } \\
\hline & 9 & 366.29 & 0.58 & 348.60 & 0.08 \\
\hline & 5 & 537.87 & 0.86 & 478.61 & 0.11 \\
\hline \multirow{6}{*}{ Optimistic } & & \multicolumn{4}{|c|}{ Within } \\
\hline & 9 & 14.07 & 0.02 & 122.21 & 0.03 \\
\hline & 5 & 20.19 & 0.03 & 172.51 & 0.04 \\
\hline & & \multicolumn{4}{|c|}{ Free } \\
\hline & 9 & 97.19 & 0.15 & 95.69 & 0.02 \\
\hline & 5 & 142.57 & 0.23 & 132.41 & 0.03 \\
\hline
\end{tabular}

Note: This table reports the number of migrants in thousands and in percent of the overall population in the UK and the EU, respectively, as a response to the Brexit. We distinguish two scenarios (pessimistic and optimistic) and two values for the elasticity of substitution $(\sigma=9$ and $\sigma=5)$. For the optimistic scenario we assume trade costs for EU-UK trade flows to increase by 3.7 percent; for the pessimistic scenario by 13.9 percent. We further distinguish between migration Within the UK and the EU and Free migration across all countries. Agglomeration and congestion elasticities are set to $\alpha=0.1$ and $\beta=-0.3$.

is less than the corresponding number in the within-scenario. These figures make up 0.58 percent of the British population and 0.08 percent of the population in the other European countries. Reducing the elasticity of substitution to $\sigma=5$ raises migration to about 700,000 or by roughly 40 percent with internal migration and to more than one million migrants in total if we impose a lower elasticity of substitution of $\sigma=5$. In the latter case, more than 530,000 people or 0.86 percent of the British population would leave the UK to settle in the rest of Europe.

Turning to the more favorable optimistic scenario where trade costs only increase by 3.7 percent, overall migration sums up to values between 136,000 (only 14,000 within the UK) and 193,000 (20,000 within the UK) if labor mobility is ruled out between the UK and the EU. If we relax this assumption, overall migration adds up to 275,000 in the case of $\sigma=5$ implying an emigration of 142,000 people from the UK.

\section{Conclusions}

This paper has analyzed welfare and migration consequences of European integration using a quantitative spatial general equilibrium model similar to Allen and Arkolakis (2014). Based on a unique dataset on inter-regional trade flows in Europe, we were able to quantify the model for 1,318 European regions in 2010 to study the heterogeneous effects of trade integration across regions. 
If we raise trade costs to a level before the foundation of the European Community in 1957, welfare declines by about 1-2 percent on average. However, some remote locations face welfare losses of up to 4 percent. This sets off migration from the periphery to the center of about 8-11 million people, depending on the specification. We thus conclude that European market integration has contributed to a more equal distribution of economic activity, that is less density in the core of Europe.

Turning to the present debate of UK's withdrawal from the European Union, the Brexit, we find that Scottish regions would expect the largest welfare losses while the south of England experiences the lowest losses. Since we employ a single-sector model, welfare losses are moderate with -0.44 percent in the most unfavorable scenario. Nevertheless, as the UK is affected more severely by the Brexit than the rest of Europe, free mobility across the Channel could imply emigration of more than 500,000 people from the UK to settle other parts of Europe. This is equivalent to nearly one percent of the British population.

\section{References}

Allen, T. and C. Arkolakis. 2014. Trade and the topography of the spatial economy. Quarterly Journal of Economics, 129(3), 1085-1139.

Anderson, J. E. 1979. A Theoretical Foundation for the Gravity Equation. American Economic Review, 69, 106-16.

Anderson, J. E. and van Wincoop, E. 2003. Gravity with Gravitas: A Solution to the Border Puzzle. American Economic Review, 93, 170-192.

Armington, P. S. 1969. A Theory of Demand for Products Distinguished by Place of Production. Staff Papers (International Monetary Fund), Palgrave Macmillan Journals, 16, 159-17.

Baldwin, R. E. and Venables, A. J. 1995. Regional economic integration. Handbook of International Economics, Elsevier. Grossman, G. and Rogoff, K. (Eds.) 3, 15971644 .

Bartelme, D. 2015. Trade Costs and Economic Geography: Evidence from the U.S., Working Paper.

Behrens, K., Mion, G., Murata, Y. and Suedekum, J. 2017. Spatial frictions, Journal of Urban Economics, forthcoming.

Berden, K., Francois, J., Tamminen, S., Thelle, M. and Wymenga, P. 2013. Non-Tariff Measures in EU-US Trade and Investment: An Economic Analysis, IIDE Discussion Papers 20090806, Institute for International and Development Economics. 
Bryan, G., and M. Morten. 2014. Economic Development and the Spatial Allocation of Labor: Evidence From Indonesia, Stanford University, mimeograph.

Caliendo L, Parro F, Rossi-Hansberg E, Sarte PD. 2014. The Impact of Regional and Sectoral Productivity Changes on the U.S. Economy. NBER Working Paper 20168.

Combes, P.-P. and Gobillon, L. 2015. The Empirics of Agglomeration Economies. In: Duranton, G., Henderson, J.V. and Strange, W. (Eds.): Handbooks in Economics Regional and Urban Economics. Elsevier, Amsterdam. 247-348.

Cosar, A. K. and Fajgelbaum, P. D. 2016. Internal Geography, International Trade, and Regional Specialization. American Economic Journal: Microeconomics, 8(1), $24-56$.

Costinot, A. and Rodriguez-Clare, A. 2014. Chapter 4 - Trade Theory with Numbers: Quantifying the Consequences of Globalization. Handbook of International Economics, Elsevier. Gita Gopinath, E. H. and Rogoff, K. (Eds.) 4, 197-261.

Dhingra, S.; Huang, H.; Ottaviano, G.; Sampson, T. and Van Reenen, J. 2016. The Costs and Benefits of Leaving the EU: Trade Effects. Centre for Economic Performance.

Eaton, J. and Kortum, S. 2002. Technology, Geography, and Trade. Econometrica, 70, 1741-1779.

Head, K. and Mayer, T. 2014. Chapter 3 - Gravity Equations: Workhorse, Toolkit, and Cookbook. Handbook of International Economics, Elsevier. Gita Gopinath, E. H. and Rogoff, K. (Eds.), 4, 131-195.

Helpman, E. 1998. The size of regions. Topics in Public Economics. Theoretical and Empirical Analysis, Cambridge Univ. Press. Pines, D. and Sadka, E. and Zilcha, I. (Eds.), 33-54.

Levchenko, A. A. and Zhang, J. 2012. Comparative advantage and the welfare impact of European integration. Economic Policy, 27, 567-602.

Mayer, T. and Zignago, S. 2011. Notes on CEPII's distances measures: the GeoDist Database. CEPII Working Paper 2011-25.

Monte, F.; Redding, S. J. and Rossi-Hansberg, E. 2015. Commuting, Migration and Local Employment Elasticities. National Bureau of Economic Research.

Nitsch, V. and Wolf, N. 2013. Tear down this wall: on the persistence of borders in trade, Canadian Journal of Economics, 46(1), 154-179. 
Ottaviano, G. I. 2014. European integration and the gains from trade. Chapter prepared for the Handbook of the Economics of European Integration, Routledge. Badinger, H. and Nitsch, V. (Eds.)

Redding, S. J. 2016. Goods trade, factor mobility and welfare. Journal of International Economics, 101, 148-167.

Redding, S. J. and Sturm, D. M. 2008. The Costs of Remoteness: Evidence from German Division and Reunification. American Economic Review, 98, 1766-97.

Rosenthal, S. S. and Strange, W. C. 2004. Chapter 49 - Evidence on the nature and sources of agglomeration economies. Cities and Geography, Elsevier. Henderson, J. V. and Thisse, J.-F. (Eds.), 4, 2119 - 2171.

Simonovska, I. and Waugh, M. E. 2014. The Elasticity of Trade: Estimates and Evidence. Journal of International Economics, 92(1), 34-50.

Statistical Office of the European Communities. 2016. EUROSTAT: Regions and Cities: Regional statistics illustrated. Luxembourg: Eurostat.

United Nations. 2016. UN COMTRADE database. http://comtrade.un.org/. 


\section{Appendix}

\section{A European regional trade data}

The trade flow matrix comes from the Forecast of Nationwide Transport Relations in Germany 2030 (Verkehrsverflechtungsprognose 2030, VVP). It covers trade flows (in metric tons) that either have a German NUTS3-region as origin or destination or serve as a transit region for intra-European trade of regions outside of Germany. The data distinguish between the mode of transport, namely road, rail and water, and product groups according to NST-2007. For rail and water, the data come from the German Federal Statistical Office and for road from the Federal Motor Transport Authority (Kraftfahrtbundesamt).

For German locations trade flows are reported at the NUTS3-level. For other European countries, geographical units are more aggregated with a higher level of aggregation for more distant countries. For example, coverage for the Netherlands occurs at the NUTS2-

Table A1: Aggregate trade volumes per product Category: Comtrade vs. VVP

\begin{tabular}{|c|c|c|c|c|c|}
\hline \multirow[b]{2}{*}{ Product category } & \multicolumn{2}{|c|}{$\begin{array}{c}\text { Between } \\
\text { Germany - Rest of Europe }\end{array}$} & \multicolumn{2}{|c|}{$\begin{array}{c}\text { Between } \\
\text { Rest of Europe }\end{array}$} & \multirow{2}{*}{$\begin{array}{c}\text { Within } \\
\text { Germany } \\
\text { VVP }\end{array}$} \\
\hline & COMTRADE & $V V P$ & COMTRADE & $V V P$ & \\
\hline 10 & 14.57 & 14.46 & 106.16 & 15.29 & 155.71 \\
\hline 21 & 0.82 & 0.88 & 21.80 & 3.18 & 29.19 \\
\hline 22 & 0.32 & 0.87 & 104.16 & 0.49 & 12.45 \\
\hline 23 & 12.79 & 0.24 & 98.09 & 0.14 & 1.63 \\
\hline 31 & 0.13 & 1.67 & 12.98 & 1.40 & 15.83 \\
\hline 32 & 0.96 & 0.52 & 2.82 & 0.05 & 5.60 \\
\hline 33 & 39.53 & 35.38 & 93.85 & 1.85 & 867.64 \\
\hline 40 & 35.94 & 24.36 & 122.19 & 13.29 & 279.69 \\
\hline 50 & 1.79 & 2.81 & 6.88 & 3.33 & 10.60 \\
\hline 60 & 26.02 & 23.86 & 78.27 & 14.10 & 112.22 \\
\hline 71 & 0.72 & 1.41 & 6.68 & 0.50 & 10.24 \\
\hline 72 & 17.14 & 11.05 & 148.13 & 5.46 & 128.10 \\
\hline 80 & 42.65 & 29.47 & 131.50 & 8.18 & 136.19 \\
\hline 90 & 21.51 & 20.73 & 51.11 & 9.14 & 280.01 \\
\hline 100 & 29.08 & 25.20 & 91.92 & 15.07 & 167.88 \\
\hline 110 & 8.70 & 8.82 & 24.90 & 7.88 & 47.93 \\
\hline 120 & 9.32 & 12.00 & 23.18 & 5.88 & 68.60 \\
\hline 130 & 1.99 & 3.16 & 7.89 & 1.20 & 12.00 \\
\hline 140 & 15.42 & 12.96 & 42.64 & 6.82 & 251.62 \\
\hline 150 & . & 1.29 & . & 2.38 & 29.93 \\
\hline 160 & . & 5.59 & . & 6.06 & 68.55 \\
\hline 170 & . & 1.27 & . & 2.98 & 32.89 \\
\hline 180 & . & 10.66 & . & 6.99 & 83.95 \\
\hline 190 & . & 36.82 & . & 13.65 & 46.35 \\
\hline
\end{tabular}

Notes: This table reports aggregate trade volumes in million tons per product category. We compare values that come from COMTRADE with values from the Forecast of Nationwide Transport Relations in Germany 2030 (VVP). 
level while Portugal has no regional breakdown (NUTS0). The data were collected in a project undertaken by Intraplan Consulting, Munich, in collaboration with BVU Consulting, Freiburg, for the Federal Ministry of Transport and Digital Infrastructure and is only available for 2010. The data are made available through the Institute for Transport Research of the German Aerospace Center under http://daten.clearingstelle-verkehr.de/276/.

\section{B Data on local GDP and population}

As the model requires data on local GDP and population (density) across European regions, we plot this information in two panels of Figure A1. Darker colors indicate higher values of income and population. The data are taken from the Statistical Office of the European Union (Eurostat) and can be accessed via http://ec.europa.eu/eurostat/data/database. We use information on the gross domestic product (GDP) at current market prices by NUTS 3 regions with the code: nama_10r_3gdp; on area by NUTS-3 region with the code: demo_r_d3area; and on the average annual population to calculate regional GDP data (thousand persons) by NUTS-3 regions with the code: nama_10r_3popgdp. 


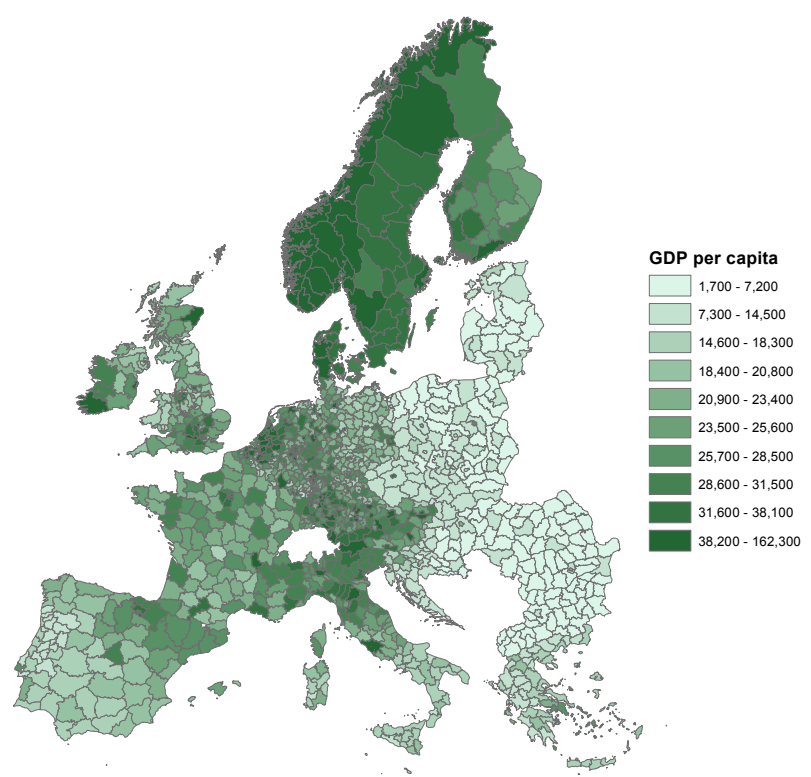

(a) GDP per capita

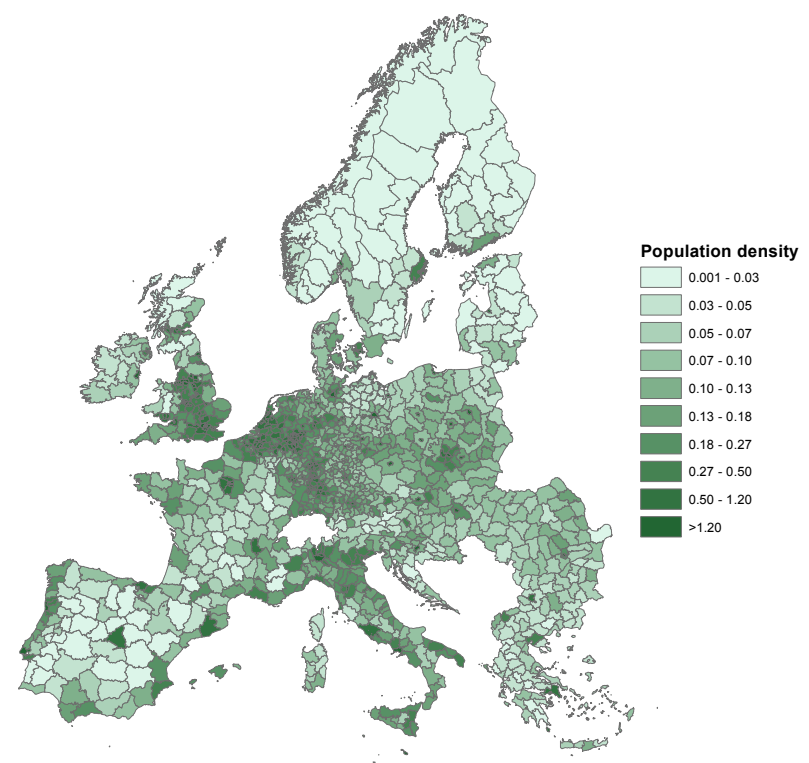

(b) Population density

Figure A1: Distribution of GDP Per Capita And Population Density in 2010

Notes: This figure plots the quantiles of the GDP per capita distribution in Panel (a) and of the population density distribution in Panel (b) for the year 2010. A darker shading indicates higher values. 


\section{Supplement (not intended for publication)}

The following two tables are replications of Table 3 for trade cost changes of 50 percent and 100 percent.

Table S1: Welfare ChANGE AND IMPLIED MigRATion FlOWS

\begin{tabular}{|c|c|c|c|c|c|c|}
\hline \multirow[b]{2}{*}{ Country } & \multicolumn{3}{|c|}{ No mobility } & \multicolumn{3}{|c|}{ International mobility } \\
\hline & $\Delta W(i)$ & $\min$ & $\max$ & $\Delta L(i)$ & $\min$ & $\max$ \\
\hline Austria & -1.37 & -1.49 & -1.03 & -1.20 & -2.28 & 0.42 \\
\hline Belgium & -0.72 & -0.75 & -0.71 & 2.25 & 2.09 & 2.29 \\
\hline Bulgaria & -2.59 & -2.85 & -2.33 & -8.75 & -9.93 & -7.05 \\
\hline Croatia & -1.64 & -2.01 & -1.50 & -3.45 & -5.27 & -2.35 \\
\hline Czech Republic & -1.25 & -1.52 & -1.06 & -1.13 & -2.44 & 0.21 \\
\hline Denmark & -1.33 & -1.43 & -1.15 & -1.17 & -1.93 & -0.33 \\
\hline Estonia & -2.50 & -2.63 & -2.32 & -7.95 & -8.74 & -7.05 \\
\hline Finland & -2.63 & -3.43 & -2.26 & -9.57 & -13.03 & -6.67 \\
\hline France & -0.82 & -1.50 & -0.67 & 0.46 & -2.35 & 2.54 \\
\hline Germany & -0.74 & -0.98 & -0.58 & 1.94 & 0.71 & 3.10 \\
\hline Greece & -2.91 & -3.54 & -2.54 & -10.01 & -13.58 & -8.20 \\
\hline Hungary & -1.73 & -1.97 & -1.53 & -3.79 & -5.04 & -2.55 \\
\hline Ireland & -1.35 & -1.58 & -1.31 & -2.08 & -2.81 & -1.28 \\
\hline Italy & -1.59 & -2.57 & -1.11 & -3.37 & -8.36 & -0.09 \\
\hline Latvia & -2.25 & -2.46 & -2.08 & -6.84 & -7.79 & -5.68 \\
\hline Lithuania & -2.12 & -2.30 & -1.97 & -5.90 & -6.89 & -5.03 \\
\hline Luxembourg & -0.76 & -0.76 & -0.76 & 2.02 & 2.02 & 2.02 \\
\hline Netherlands & -0.76 & -0.86 & -0.71 & 1.94 & 1.37 & 2.29 \\
\hline Norway & -1.82 & -3.67 & -1.52 & -5.80 & -14.33 & -2.49 \\
\hline Poland & -1.60 & -2.00 & -1.28 & -3.13 & -5.24 & -1.07 \\
\hline Portugal & -2.46 & -2.80 & -2.17 & -7.71 & -9.61 & -6.18 \\
\hline Romania & -2.52 & -2.79 & -2.03 & -7.43 & -9.59 & -5.41 \\
\hline Slovakia & -1.62 & -1.86 & -1.50 & -3.26 & -4.42 & -2.35 \\
\hline Slovenia & -1.48 & -1.53 & -1.40 & -2.20 & -2.53 & -1.76 \\
\hline Spain & -2.55 & -2.81 & -1.64 & -5.80 & -9.67 & -3.14 \\
\hline Sweden & -1.85 & -3.10 & -1.42 & -5.10 & -11.30 & -1.92 \\
\hline United Kingdom & -1.12 & -1.84 & -0.88 & -0.65 & -4.29 & 1.26 \\
\hline
\end{tabular}

Note: This table reports percentage change in welfare and population in response to a 50 percent increase of trade costs between European countries. Columns (1)-(3) assume no labor mobility and report average welfare changes per country as well as minimum and maximum values across regions. Column 4 reports the percentage change in population when we allow for labor to move freely across all locations. Columns 5 and 6 show the minimum and maximum population change in a region per country. 
Table S2: Welfare Change And IMPLiEd Migration flows

\begin{tabular}{|c|c|c|c|c|c|c|}
\hline \multirow[b]{2}{*}{ Country } & \multicolumn{3}{|c|}{ No mobility } & \multicolumn{3}{|c|}{ International mobility } \\
\hline & $\Delta W(i)$ & $\min$ & $\max$ & $\Delta L(i)$ & $\min$ & $\max$ \\
\hline Austria & -2.55 & -2.77 & -1.92 & -2.55 & -4.55 & 0.45 \\
\hline Belgium & -1.36 & -1.40 & -1.35 & 3.81 & 3.55 & 3.87 \\
\hline Bulgaria & -4.83 & -5.31 & -4.34 & -16.14 & -18.18 & -13.19 \\
\hline Croatia & -3.06 & -3.76 & -2.80 & -6.72 & -10.04 & -4.71 \\
\hline Czech Republic & -2.34 & -2.83 & -1.98 & -2.43 & -4.87 & 0.08 \\
\hline Denmark & -2.50 & -2.68 & -2.18 & -2.66 & -4.02 & -1.13 \\
\hline Estonia & -4.68 & -4.93 & -4.36 & -14.90 & -16.28 & -13.33 \\
\hline Finland & -4.93 & -6.40 & -4.24 & -17.73 & -23.61 & -12.70 \\
\hline France & -1.55 & -2.78 & -1.27 & 0.47 & -4.56 & 4.37 \\
\hline Germany & -1.36 & -1.78 & -1.07 & 3.50 & 1.26 & 5.63 \\
\hline Greece & -5.42 & -6.56 & -4.73 & -18.32 & -24.32 & -15.21 \\
\hline Hungary & -3.23 & -3.68 & -2.86 & -7.33 & -9.60 & -5.06 \\
\hline Ireland & -2.58 & -3.01 & -2.52 & -4.60 & -5.94 & -3.10 \\
\hline Italy & -2.97 & -4.78 & -2.09 & -6.55 & -15.43 & -0.54 \\
\hline Latvia & -4.22 & -4.60 & -3.90 & -12.93 & -14.59 & -10.87 \\
\hline Lithuania & -3.97 & -4.30 & -3.69 & -11.24 & -13.01 & -9.69 \\
\hline Luxembourg & -1.43 & -1.42 & -1.42 & 3.43 & 3.43 & 3.43 \\
\hline Netherlands & -1.44 & -1.64 & -1.35 & 3.20 & 2.12 & 3.86 \\
\hline Norway & -3.44 & -6.84 & -2.89 & -11.12 & -25.70 & -5.24 \\
\hline Poland & -2.99 & -3.75 & -2.39 & -6.14 & -10.00 & -2.33 \\
\hline Portugal & -4.63 & -5.24 & -4.11 & -14.59 & -17.83 & -11.93 \\
\hline Romania & -4.70 & -5.19 & -3.80 & -13.84 & -17.59 & -10.26 \\
\hline Slovakia & -3.03 & -3.47 & -2.80 & -6.36 & -8.49 & -4.68 \\
\hline Slovenia & -2.76 & -2.86 & -2.61 & -4.43 & -5.04 & -3.61 \\
\hline Spain & -4.77 & -5.25 & -3.09 & -11.14 & -17.86 & -6.32 \\
\hline Sweden & -3.48 & -5.81 & -2.68 & -9.86 & -20.74 & -4.05 \\
\hline United Kingdom & -1.94 & -3.15 & -1.54 & -0.58 & -6.70 & 2.72 \\
\hline
\end{tabular}

Note: This table reports percentage change in welfare and population in response to a 100 percent increase of trade costs between European countries. Columns (1)-(3) assume no labor mobility and report average welfare changes per country as well as minimum and maximum values across regions. Column 4 reports the percentage change in population when we allow for labor to move freely across all locations. Columns 5 and 6 show the minimum and maximum population change in a region per country. 